\title{
Response to Letter to the Editor: Reflux Esophagitis and Marginal Ulcer After Pancreaticoduodenectomy
}

\author{
Jin-Ming Wu • Meng-Kun Tsai • Rey-Heng Hu • \\ Kin-Jen Chang $\cdot$ Po-Huang Lee $\cdot$ Yu-Wen Tien
}

Received: 1 September 2011 / Accepted: 26 October 2011 /Published online: 8 March 2012

(C) 2012 The Society for Surgery of the Alimentary Tract

We thank Dr. Selina Buchner et al. for their careful review and thoughtful comments on our recent article. ${ }^{1}$ First, we apologized for the mistake of inconsistent data in the result and discussion part. The correct result is listed below. There are 158 patients undergoing PD in our study, including 109 PD with uncut roux-en-Y method and 49 conventional antecolic gastrojejunostomy. There are seven reflux esophagitis after uncut R-Y method $(n=109)$ and eight reflux esophagitis after conventional antecolic gastrojejunostomy $(n=49)$. The $P$ value is 0.042 . On the other hand, there were 213 patients receiving PPPD, including 157 PPPD with uncut roux-en-Y method and 56 PPPD with antecolic duodenojejunostomy. There are 16 reflux esophagitis after uncut roux-en-Y method $(n=157)$ and 9 reflux esophagitis after antecolic duodenojejunostomy method $(n=56)$.

About the diagnosis of patients in our study, there are 261 cancer, 42 chronic pancreatitis, and 68 benign pancreatic diseases. There are $116(73.4 \%)$ cancer patients receiving $\mathrm{PD}$, and 145 (68.1\%) cancer patients undergoing
PPPD. Actually we found recannulation of the afferent loop after TA staplers proved by a Hypaque flow study or surgical findings for another laparotomy before. As a result, we routinely put additional two rows of 2-0 silk horizontal mattress sutures above and below the TA staplers line to prevent recannulation of afferent loop. We believe that the incidence of recannulation was very low after the above procedures. If fistula through the intestinal block by the TA staplers is suspected, the integrity of the intestines may be checked by endoscope or UGI series. Nevertheless, we do not routinely arrange image study or endoscopy to check the afferent loop.

\section{References}

Wu JM, Tsai MK, Hu RH, et al. Reflux esophagitis and marginal ulcer after pancreaticoduodenectomy. J Gastrointest Surg. 2011;15 (5):824-828.

J.-M. Wu • M.-K. Tsai • R.-H. Hu • K.-J. Chang • P.-H. Lee •

Y.-W. Tien $(\bowtie)$

Division of General Surgery, Department of Surgery,

National Taiwan University Hospital,

7 Chung-Shan South Rd.,

Taipei 10002, Taiwan, Republic of China

e-mail: ywtien5106@ntu.edu.tw

J.-M. Wu • M.-K. Tsai • R.-H. Hu • K.-J. Chang • P.-H. Lee •

Y.-W. Tien

National Taiwan University College of Medicine,

Taipei, Taiwan, Republic of China 